\title{
Empirical studies of employment and performance of scientists and engineers
}

\author{
Andries de Grip ${ }^{\mathrm{a}, \mathrm{b} *}$, Bronwyn H. Hall ${ }^{\mathrm{c}, \mathrm{d}, \mathrm{e}, \mathrm{f}}$ and Wendy Smits ${ }^{\mathrm{a}, \mathrm{g}}$ \\ ${ }^{a}$ Research Centre for Education and the Labour Market (ROA), Maastricht University, Maastricht, \\ The Netherlands; ${ }^{b}$ Institute for the Study of Labor (IZA), Bonn, Germany; ${ }^{c}$ University of California, \\ Berkeley, USA; ${ }^{d}$ UNU-MERIT, Maastricht University, Maastricht, The Netherlands; ${ }^{e}$ National \\ Bureau of Economic Research, Cambridge, MA, USA; ${ }^{f}$ Institute for Fiscal Studies (IFS), London, \\ UK; ${ }^{g}$ Statistics Netherlands, Heerlen, The Netherlands
}

(Final version received 22 October 2009)

\begin{abstract}
Policy makers in both the USA and Europe are aware of the necessity to stimulate the employment as well as the performance of scientists and engineers. This issue includes a selection of papers on both topics, bringing together labour economists as well as economists who do research on innovation and $R \& D$.
\end{abstract}

Keywords: labour market scientists and engineers; employment and performance

\section{Introduction}

As scientists and engineers (SEs) are the key actors in both product and process innovation, they will be crucial for the future competitiveness of developed countries. For this reason, policy makers in the USA and Europe as well as the emerging economies are aware of the necessity to stimulate both employment and performance of SEs. However, both in the USA and Europe the share of the world's SE graduates is declining rapidly, and even during the current economic crisis many European countries face shortages of SEs (e.g. INSEAD 2009). Moreover, due to the decreasing number of youngsters who choose a science or engineering study, these shortages may become more severe in the near future when the greying 'baby boom' generation that was born in the late 1940s will retire. As in the USA, there is a rising awareness that Europe's comparative advantages in various high-tech industries are at risk when the current shortages of SEs increase. It is likely that R\&D will be reallocated towards the emerging economies, such as China and India, as a consequence. In such countries, there is ample supply of SEs whose skill level is expected to increase rapidly in the next years (Freeman 2006). Obviously, it is not merely the number of SEs that determines a country's international competitiveness but also the quality, i.e. the performance of the SEs matters.

\footnotetext{
*Corresponding author. Email: a.degrip@maastrichtuniversity.nl
} 
For this reason, this issue presents a set of papers selected from those presented at a conference in May 2008 that focused on both the employment and the performance of SEs. The goal was to bring together a collection of papers from two usually separated lines of research. Both among labour economists and economists who do research on innovation and $R \& D$, there has been an increasing interest in research on the labour market of SEs. However, the interaction between these two groups of researchers is still rather weak.

The studies included in this issue focus on the employment and performance of SEs from three different perspectives. We will start this issue from the globalization perspective which looks at the globalization process as such and the determinants of international migration. This perspective focuses on the importance of a highly competent SE workforce for a country's competitive power in world markets as well as the 'War for talent' in the international labour markets. Then, the issue goes further into the individual perspective of SEs, focusing on the choice of R\&D jobs, entrance into an academic career, and the character of the labour market where SEs are employed. This perspective increases our insights into the preferences of young scientists and the labour market institutions that might affect their careers (cf. De Grip and Willems 2003). The issue finishes with two papers from the performance perspective. Both papers focus on the performance of academic scientists in terms of scientific publications. The first looks at the impact of electronic communication and the internet on performance and the second examines the impact of the brain drain from universities to industry on research performance.

\section{Studies on employment and performance}

\section{Globalization and international mobility}

Richard B. Freeman explores the recent globalization of SE knowledge and the economic impact of this globalization process. He distinguishes five related tracks of globalization. First, he discusses the worldwide expansion of higher education. Whereas the number of enrolments in higher education in the USA doubled between 1970 and 2006, the enrolments in the developing countries increased more than six-fold. The relative growth of $\mathrm{PhD}$ graduates in SEs was highest in China that will probably produce more SEs doctorates than the USA by 2010 . Second, there has been a tremendous growth in the number of students who study abroad, particularly in SE. Third, increasing shares of SEs employed in the advanced economies are foreign-born. Many of these SE immigrants have been international students in the country where they are now employed. Fourth, there has been a tremendous boost in academic visitors who join foreign universities for relatively long periods as well as SEs who participate in diverse international conferences and meetings. Fifth, the globalization of knowledge shows up in the increasing share of research articles published by authors employed in developing countries. In addition, the number of papers with co-authors from different countries increased greatly. Freeman also discusses the increase in productivity due to the globalization of knowledge when more and more research teams all over the world contribute to the same field of research. However, the globalization of SE knowledge also reduces the competitive advantage of advanced countries in producing high-tech goods and services. Nevertheless, the increase in the number of top quality universities gives students in both the developing and advanced countries a greater choice to attain high-level education. Freeman concludes with the output effects related to the major choice advanced countries face between off-shoring SE employment to less costly countries and attracting immigrant SEs.

Andries de Grip, Didier Fouarge and Jan Sauermann further explore the factors that affect labour migration of SEs. They show that the migration of SE graduates between EU countries 
is driven by wage differences between countries, as one would expect. Moreover, high R\&D expenditures in recipient countries attract SE graduates from other countries because of the better labour market prospects for SEs in countries with high R\&D intensities. Qualitative aspects of the jobs such as skill utilization and involvement in innovation do not affect the migration decisions of SEs, except to the extent they are related to R\&D intensities or wages. De Grip et al. also examine the personal characteristics that encourage SE graduates to find a job in another country. Previous migration experience during adolescence and previous migration experience of their parents has a strong impact. In addition, graduates who participated in an international student exchange programme are more likely to migrate to another country after graduation. Migration is found to be selective on students' average grade. Those with high grades are more likely to migrate, particularly to the USA, Canada or Australia. The latter countries are successful in recruiting SE graduates from Europe mainly because of their high R\&D expenditures. De Grip et al. conclude that the student exchange programme of the European Union is a good means of facilitating the labour market mobility of SEs within the European Union. Furthermore, the paper shows that countries can gain in the international 'war for SE talent' by offering attractive studies and internships for foreign exchange students. These strategies are particularly interesting because it is the graduates with the highest grades who migrate to another country.

\section{Employment}

Three studies in this special issue deal with different aspects of the individual labour market perspectives of a scientist or engineer. Arnaud Dupuy and Wendy Smits consider the preferences of Dutch SEs for working in R\&D functions. Shortages of R\&D workers are often attributed to low wages in R\&D. Although SEs working in R\&D generally earn less than SEs working in other functions (earnings regressions show an R\&D wage penalty of about $3.5 \%$ ), these lower wages may reflect a preference effect. If $R \& D$ workers have a strong preference for R\&D work, they may be prepared to accept lower wages. Dupuy and Smits try to measure the extent to which lower wages in $R \& D$ reflect preferences. They show that traditional measures of $R \& D$ compensating wage differentials obtained using earnings regressions are severely biased downwards, due to differences in the quality of workers in the two sets of jobs. Using direct measures of the willingness to accept and the willingness to pay for a $R \& D$ job they show that the relative wage reduction accepted by the average R\&D worker ranges from $19 \%$ to $22 \%$. The policy implication of these findings is that wage policies will be very inefficient in increasing the number of R\&D workers. Relatively low wages in $R \& D$ do not hinder the retention of $R \& D$ workers as for this group low wages are compensated for by other aspects of R\&D work. However, to persuade non-R\&D workers to switch to $R \& D$ functions, wages in $R \& D$ would have to increase greatly.

Liliane Bonnal and Jean-François Giret consider the entrance of young $\mathrm{PhD}$ graduates into a permanent position in the French academic sector. In France, as in many other countries, the supply of tenured positions in the academic sector falls short of demand. As a result the number of short term contracts and post-doctoral posts has increased in recent years. Bonnal and Giret argue that post-doc positions act as a means of reducing the asymmetric information with regard to the teaching and research skills of the applicant. In France, this asymmetric information problem is especially an issue because of certain characteristics of the French recruitment procedure in academia. Applicants are in general very young, meaning that the period to observe scientific output is very short, and after having been selected through a national selection procedure, only have a very short audition of about 
30 minutes at the university that posted the vacancy. For the French academic employers, this recruitment procedure leads to a high uncertainty on the scientific productivity of applicants. Therefore they may use post-doc positions as a means of screening potential candidates for permanent jobs in their institutions. Bonnal and Giret find that post-doc positions indeed have an influence on the length of time before achieving a permanent job in chemistry and life sciences, and to a lesser extent, in math, physics and applied sciences. However, post-docs are not rewarded in human and social sciences.

Geoff Mason and Hiroatsu Nohara compare the financial benefits of inter-firm mobility with the returns to tenure in SEs' current firms. They expect that external experience has become more valuable for firms that face increasing competitive pressure to acquire knowledge which has been developed beyond their own boundaries. This in turn may contribute to the ongoing decline of 'internal labour markets' in which firms develop their own firm-specific human capital. In order to assess whether this shift from internal to external labour markets is affected by different national education and labour market institutions, Mason and Nohara compare developments in the UK (where the portability of initial qualifications has traditionally facilitated individual mobility between enterprises) and France, where engineers have traditionally had lengthy pre-employment training placements inside firms prior to their recruitment to entry-level positions with prospects for internal promotion. They find that returns to tenure for SEs are decreasing in both countries although they still remain higher in France than in the UK. However, they do not find any evidence that external experience has actually become more valuable for firms than internal experience. In both countries, the average returns to external experience are roughly equal to the returns for firm tenure. Mason and Nohara suggest that, although firms make more use of external recruitment and knowledge sources, they still also rely on the tacit knowledge of some SEs with long firm tenures. That is, firms attempt to balance knowledge acquisition through external recruitment with retention of key SEs who possess firm-specific knowledge and experience. From the individual perspective, there is, however, a striking difference between the UK and France. In the UK, the returns to external mobility vary greatly between SEs who have been laid off and SEs who voluntarily quit their previous firms, whereas in France many SEs benefit from long firm tenures but the small group who move to other firms are well rewarded for doing so.

\section{Performance}

This special issue includes two papers that deal with the performance of scientists in terms of their research productivity. Anne E. Winkler, Sharon G. Levin and Paula E. Stephan study the impact of various IT innovations on academic researchers in the USA. Two indicate 'connectivity' - BITNET and the introduction of the domain name system that is essential for Internet communications, and two indicate 'research-related IT' - the availability of electronic journals via JSTOR, and off-campus access to electronic library resources. The authors find modest evidence that these innovations increased researcher productivity at all institutions and improved the productivity of researchers at lower-relative to higherranked institutions. However, contrary to their expectations that such innovations benefit less mobile researchers more, these innovations did not have a differential benefit for female over male researchers.

In a study of biomedical academic scientists in the USA, Dirk Czarnitzki and Andrew A. Toole analyse to what extent research productivity is affected when academic scientists pursue commercialization activities in the private sector. They find that those who moved to private-sector firms were more productive in scientific journal article publications during 
their university careers than biomedical scientists who remained employed in academe. However, Czarnitzki and Toole do not find any evidence for a 'fertile pasture' in research productivity. Indeed, while scientists are employed in the private sector, their research productivity falls. Moreover, those who return to the academic world after some time are less productive than they were before they moved to the private sector. These findings indicate that there is a trade-off between the production of public scientific knowledge and the knowledge transfer to the private sector when highly productive academic scientists move to the business world. Czarnitzki and Toole suggest that the growing public policies efforts encouraging the mobility of academic researchers to the private sector may therefore be a short-sided policy that undermines economic growth in the long run.

The rich sets of findings of the papers included in this special issue contribute to our insights into the employment and performance of SEs. We believe that further research in this field could benefit a lot from closer co-operation between economists who analyse the innovativeness and performance of SEs and labour economists whose major research interest focuses on career choices and the functioning of the labour market of SEs. This cooperation will be facilitated by the further development of matched employee-firm data that cover employee and job characteristics as well as indicators on R\&D investment, measures of innovation and firm performance.

\section{References}

De Grip, A. and E. Willems. 2003. Youngsters and technology. Research Policy 32: 1771-81.

Freeman, R.B. 2006. Does globalization of the scientific/engineering workforce threaten economic leadership? Innovation Policy and the Economy 6: 123-58. (Also NBER Working Paper 11457, Cambridge, MA.)

INSEAD. 2009. Who cares? Who dares? Providing the skills for an innovative and a sustainable Europe. Fontainebleau, France: INSEAD. 
